\title{
Effects of Atorvastatin and Insulin in Vascular Dysfunction Associated With Type 2 Diabetes
}

\author{
C. M. SENA ${ }^{1,2}$, P. MATAFOME ${ }^{1,2}$, T. LOURO $^{1,2}$, E. NUNES ${ }^{1}$, R. M. SEIÇA ${ }^{1,2}$ \\ ${ }^{1}$ Physiology, Faculty of Medicine, University of Coimbra, Portugal, ${ }^{2}$ IBILI, Faculty of Medicine, \\ University of Coimbra, Portugal
}

Received April 19, 2013

Accepted August 20, 2013

On-line January 8, 2014

\begin{abstract}
Summary
Atorvastatin and insulin have distinct mechanisms of action to improve endothelial function. Therefore, we hypothesized that atorvastatin and insulin therapies alone or in combination could have beneficial effects on endothelium-dependent vascular reactivity, oxidative stress, inflammation and metabolic parameters in Goto-Kakizaki (GK) rats, a model of type 2 diabetes fed with atherogenic diet (GKAD). In parallel with the development of diabetes and lipid profile, the generation of oxidative stress was determined by measurement of lipid peroxides and oxidized proteins and the presence of inflammation was evaluated by assessing C-reactive protein (CRP). Additionally, endothelial dependent and independent vascular sensitivity to acetylcholine and sodium nitroprusside were evaluated. GKAD showed increased carbonyl stress, inflammation, fasting glycemia, dyslipidemia and endothelial dysfunction when compared to control GK rats. Noteworthy, supplementation with insulin deteriorated endothelial dysfunction while atorvastatin induced an improvement. Atorvastatin and insulin therapies in combination improved metabolic parameters, CRP levels and insulin resistance indexes and ameliorated endothelial dysfunction in GKAD rats while they were unable to reduce urinary 8 -isoprostranes and plasma carbonyl compounds. The therapeutic association of atorvastatin and insulin provided a better metabolic control with a reduction in endothelial dysfunction in GKAD rats by a mechanism that involves an improvement in systemic inflammation.
\end{abstract}

\section{Key words}

Endothelial dysfunction • Type 2 diabetes • Insulin • Atorvastatin - Goto-Kakizaki rats

\section{Corresponding author}

C. M. Sena, Institute of Physiology, Sub-unidade 1, Pólo III, Faculty of Medicine, University of Coimbra, Azinhaga de Santa Comba, Celas, 3000-504 Coimbra, Portugal. Fax: +351-239480034. E-mail: csena@ci.uc.pt

\section{Introduction}

3-Hydroxy-3-methylglutaryl coenzyme A reductase inhibitors (statins) are more than just cholesterol lowering drugs (Koh et al. 2011). The effects of statins in the cardiovascular system include, among others, the improvement of endothelium-dependent relaxation through a mechanism that involves endothelial nitric oxide synthase up-regulation, a reduction in the progression of arteriosclerosis, an antihypertensive effect and beneficial actions on cardiac function (Takemoto and Liao 2001, Ii and Losordo 2007).

Insulin plays an important role in maintaining both hemodynamic and metabolic homeostasis under healthy conditions. Insulin has important vascular actions to stimulate production of nitric oxide (NO) from endothelium. This leads to capillary recruitment, vasodilation, increased blood flow, and subsequent augmentation of glucose disposal in classical insulin target tissues. Thus, insulin treatment not only reduces glycemia but may also directly increase NO production through 1-phosphotidylinositol 3-kinase (PI-3K) signalling (Muniyappa et al. 2007). In insulin-resistant states, the selective impairment in the PI-3K/Akt/endothelial nitric oxide synthase (eNOS) pathway and the augmented ERK1/2 signaling cascade in vascular endothelium lead to decreased NO availability 
and enhanced endothelin-1 (ET-1) production, thereby tilting the balance between the vasodilator and vasoconstrictor actions of insulin toward endothelial dysfunction and hypertension (Huang 2009).

Atorvastatin and insulin have distinct mechanisms of action to improve endothelial function. Therefore, we hypothesized that combination therapy has additive beneficial effects to simultaneously improve endothelial dysfunction, inflammation and oxidative stress profiles in GK rats fed with an atherogenic type of diet.

\section{Methods}

\section{Experimental animals}

Goto-Kakizaki rats were obtained from our local breeding colony (Animal Research Center Laboratory, University Hospital, Coimbra, Portugal). Rats were divided in 5 experimental groups accordingly [GK diabetic rats fed with a normal diet (GK control), GK diabetic rats fed with an atherogenic diet (AD, GKAD), and $\mathrm{GK}$ rats fed an $\mathrm{AD}$ diet treated with atorvastatin $(\mathrm{GKAD}+\mathrm{A})$, insulin $(\mathrm{GKAD}+\mathrm{I})$ or the association of atorvastatin and insulin $(\mathrm{GKAD}+\mathrm{A}+\mathrm{I})]$. Special high fat $\operatorname{diet}(\mathrm{AD})$ was obtained from Safe (France) and contained $70 \%$ AO4 standard chow diet, $7.5 \%$ cocoa butter, and $1.25 \%$ cholesterol. The animals were maintained with $\mathrm{AD}$ diet between 2 and 6 months of age. All the animals were used with 6 months old.

All animals received care in accordance with the Portuguese Law on Experimentation with Laboratory Animals (last amendment, 2004), which is based on the principles of laboratory animal care as adopted by the EC Directive 86/609/EEC for animal experiments.

\section{Treatment administration}

Insulin and atorvastatin were administered during one month (between 5 and 6 month old) before sacrifice. Insulin (Mixtard 30 Novolet, from Novo Nordisk A/S, Denmark) was administered twice a day subcutaneously according to glucose levels: glycemia between 150 and $199 \mathrm{mg} / \mathrm{dl}, 2 \mathrm{U}$ of insulin; glycemia between 200 and $299 \mathrm{mg} / \mathrm{dl}, 4 \mathrm{U}$ of insulin; glycemia higher than $300 \mathrm{mg} / \mathrm{dl}$, $6 \mathrm{U}$ of insulin. Atorvastatin (Pfizer, USA) was administered orally $(10 \mathrm{mg} / \mathrm{kg} /$ day $)$ diluted in water.

Determination of metabolic and oxidative stress parameters

After a $15 \mathrm{~h}$ fast, animals were anesthetized with ketamine/chlorpromazine [ketamine chloride $(75 \mathrm{mg} / \mathrm{kg}$, im, Parke-Davis, Ann Arbor, MI, USA) and chlorpromazine chloride $(2.65 \mathrm{mg} / \mathrm{kg}$, im, Lab. Vitória, Portugal)] and killed by decapitation. Blood was taken by heart puncture for determination of lipids, carbonyl compounds and insulin. Fasting plasma lipids (total and HDL cholesterol and triglycerides, Olympus-Diagnóstica Portugal, Produtos de Diagnóstico SA, Portugal) and plasma insulin levels were quantified using commercially available kits and by an in-house enzyme-linked immunosorbent assay, respectively. Plasma free fatty acids (FFA) levels were evaluated using enzymatic assay kits (Roche Applied Science, Portugal). Rats were placed in metabolic cages for $24 \mathrm{~h}$ and urine collected. Urinary 8-isoprostanes (OXIS health Products, Portland, OR, USA), $\mathrm{C}$ reactive protein (CRP; BD Biosciences Pharmingen, CA, USA) and plasma carbonyl protein concentrations (Cayman Chemical Company, USA) were measured using ELISA kits.

For glucose tolerance tests, rats were fasted overnight and were given an intraperitoneal injection of glucose (1.75 $\mathrm{g} \mathrm{kg}^{-1}$ body weight). Blood glucose was determined by sampling from the tail vein at 0 , and $120 \mathrm{~min}$ after injection by a glucose-oxidase method using a glucometer (Glucometer-Elite-Bayer, Portugal S.A.) and compatible reactive test strips. To assess insulin resistance in the fasted state, the homeostasis model assessment of insulin resistance (HOMA) and quantitative insulin-sensitivity check index (QUICKI), were calculated, as previously described (Sena et al. 2008). HOMA was calculated as $\left[\left(\mathrm{G}_{0}\right) \mathrm{x}\left(\mathrm{I}_{0}\right) / 22.5\right]$ where $\mathrm{G}_{0}$ is the fasting glucose levels (mmol/l) and $\mathrm{I}_{0}$ is the fasting insulin levels $(\mu \mathrm{U} / \mathrm{ml})$. QUICKI was calculated as $1 /\left[\log \left(\mathrm{G}_{0}\right)+\log \left(\mathrm{I}_{0}\right)\right]$, where $\mathrm{G}_{0}$ is fasting glycemia $(\mathrm{mg} / \mathrm{dl})$ and $I_{0}$ is fasting insulin levels $(\mu \mathrm{U} / \mathrm{ml})$. Index of atherogenicity was calculated as total cholesterol/HDLcholesterol.

\section{Aortic nitrite levels}

Nitrite levels were determined as an index of NO generation in aortic homogenates by the Griess reaction after conversion of nitrate to nitrite by nitrate dehydrogenase as previously described (Majithiya et al. 2005). An aliquot of the supernatant was mixed with an equal volume of Griess reagent (Sulfanilamide $1 \% \mathrm{w} / \mathrm{v}$; naphtylethylenediamine dihydrochloride, $0.1 \% \mathrm{w} / \mathrm{v}$; and orthophosphoric acid, $25 \% \mathrm{v} / \mathrm{v}$ ) and incubated at room temperature for $10 \mathrm{~min}$. The absorbance of the samples at $540 \mathrm{~nm}$ was determined and compared with those of known concentrations of sodium nitrite. The amount of 
Table 1. Influence of atorvastatin (GKAD+A), insulin (GKAD+I) and the association of both (GKAD+A+I) on body weight, blood glucose (fasting glucose - FBG and $2 \mathrm{~h}$ glycemia), insulin levels and insulin resistance indexes (HOMA and QUICKI) in atherogenic diet fed GK (GKAD) rats (mean \pm SEM of 8-16 animals).

\begin{tabular}{|c|c|c|c|c|c|}
\hline & GK & GKAD & GKAD+A & GKAD+I & $\mathbf{G K A D}+\mathbf{A}+\mathbf{I}$ \\
\hline $\begin{array}{l}\text { Body weight } \\
\text { (g) }\end{array}$ & $345.2 \pm 8.4$ & $387.3 \pm 4.3^{\S \S \S}$ & $400.9 \pm 7.0^{\S \S \S}$ & $391.7 \pm 5.0^{\S \S \S}$ & $390.8 \pm 5.1^{\S \S \S}$ \\
\hline $\begin{array}{l}\text { Diet } \\
\text { (g/rat/day) }\end{array}$ & $23 \pm 0$ & $19 \pm 2$ & $20 \pm 1$ & $19 \pm 1$ & $18 \pm 1$ \\
\hline $\begin{array}{l}F B G \\
(\mathrm{mg} / \mathrm{dl})\end{array}$ & $93.1 \pm 2.5$ & $140.2 \pm 2.8^{\S \S \S}$ & $118.2 \pm 2.3^{\phi \phi \phi}$ & $97.3 \pm 2.1^{\phi \phi \phi}$ & $91.0 \pm 1.2^{\phi \phi \phi}$ \\
\hline $\begin{array}{l}\text { Glycemia at } 2 \mathrm{~h} \\
(\mathrm{mg} / \mathrm{dl})\end{array}$ & $299.4 \pm 7.2$ & $303.2 \pm 14.9$ & $288.3 \pm 10.1$ & $268.5 \pm 13.7$ & $222.5 \pm 11.9^{\phi \phi \phi}$ \\
\hline $\begin{array}{l}\text { Insulin } \\
(\mu U / m l)\end{array}$ & $37.0 \pm 3.4$ & $32.8 \pm 5.6$ & $25.1 \pm 3.0$ & $23.9 \pm 4.3$ & $21.7 \pm 5.3$ \\
\hline HOMA & $11.2 \pm 1.3$ & $14.7 \pm 2.5$ & $7.3 \pm 0.8^{\phi}$ & $5.3 \pm 1.0^{\phi \phi}$ & $4.8 \pm 1.2^{\phi \phi}$ \\
\hline QUICKI & $0.286 \pm 0.01$ & $0.271 \pm 0.01$ & $0.292 \pm 0.01^{\phi}$ & $0.309 \pm 0.01^{\phi \phi \phi}$ & $0.320 \pm 0.01^{\phi \phi \phi}$ \\
\hline
\end{tabular}

$\S \S \S \mathrm{P}<0.001$ vs $\mathrm{GK}$ rats; $\phi \mathrm{P}<0.05, \phi \phi \mathrm{P}<0.01, \phi \phi \phi \mathrm{P}<0.001$ vs GKAD rats.

nitrite formed was normalized to the protein content of the respective aorta.

\section{Isometric tension studies}

Aorta were rapidly excised and freed of connective tissue. The aorta was divided into two segments (4-mm width). Ring segments were mounted between stainless steel triangles into individual organ chambers filled with oxygenated $\left(95 \% \mathrm{O}_{2}, 5 \% \mathrm{CO}_{2}\right)$ modified Krebs-Henseleit buffer $\left(37^{\circ} \mathrm{C}, \quad \mathrm{pH}\right.$ 7.4) (composition in $\mathrm{mM}: \mathrm{NaCl} 119, \mathrm{KCl} 4.7, \mathrm{CaCl}_{2}$ 1.6, $\mathrm{MgSO}_{4}$ 1.2, $\mathrm{NaHCO}_{3} 25, \mathrm{KH}_{2} \mathrm{PO}_{4}$ 1.2, Glucose 11.0). Indomethacin in a concentration of $10 \mu \mathrm{M}$ was present in the experiments to inhibit prostaglandin synthesis. Aortic rings were subject to a resting tension of $14.7 \mathrm{mN}$. After equilibration for $60 \mathrm{~min}$ all vessels were preconstricted with $0.3 \mu \mathrm{M}$ phenylephrine. Ligand stimulated receptormediated NO bioavailability was assessed by a concentration-dependent relaxation to acetylcholine (ACh, $10^{-9}$ to $10^{-2} \mathrm{M}$ ), whereas sodium nitroprusside (SNP, $10^{-9}$ to $10^{-3} \mathrm{M}$ ) was used as an endotheliumindependent agonist. Relaxation responses to $\mathrm{ACh}$ and SNP were expressed as percentage of relaxation from a submaximal phenylephrine-induced constriction and dose-response curves were obtained as previously described (Sena et al. 2008, 2011).

\section{Statistical analysis}

All data were analyzed by standard computer programs (GraphPad Prism PC Software version 3.0, ANOVA) and are expressed as mean \pm SEM ( $n=16$ individual animals per group). Significant differences were evaluated using either the $t$-test or ANOVA. $\mathrm{P}<0.05$ was considered significant. Dose response curves were fitted by nonlinear regression with simplex algorithm. Relaxation responses were given as the percentage of phenylephrine-preconstriction. Comparisons of doseresponse curves were evaluated by 2-way ANOVA for repeated measures.

\section{Results}

Atherogenic diet resulted in an increase in body weight and fasting glycemia, while no changes were observed in insulin resistance, when compared with GK control rats. Food consumption was similar in all the experimental groups (Table 1). Treatment with atorvastatin significantly reduced fasting blood glucose and ameliorated insulin resistance indexes. Treatment with insulin had similar effects. The therapeutic combination of atorvastatin and insulin significantly reduced fasting and $2 \mathrm{~h}$ glycemia and further improved insulin resistance indexes when compared with GKAD rats (Table 1).

GKAD rats exhibited higher levels of triglycerides, total-cholesterol and FFAs when compared to diabetic control rats, as well as an elevated atherogenic index, while HDL-cholesterol levels were significantly 
Table 2. Effects of atorvastatin $(G K A D+A)$, insulin $(G K A D+I)$ and the association of both $(G K A D+A+I)$ on lipid profile (triglycerides, total and HDL-cholesterol and free fatty acids, FFAs) and atherogenic index in atherogenic diet fed GK (GKAD) rats (mean \pm SEM of 8-16 animals).

\begin{tabular}{|c|c|c|c|c|c|}
\hline & GK & GKAD & GKAD+A & GKAD+I & $\mathbf{G K A D}+\mathbf{A}+\mathbf{I}$ \\
\hline $\begin{array}{l}\text { Triglycerides } \\
(m g / d l)\end{array}$ & $149.5 \pm 11.6$ & $222.9 \pm 20.0^{\S \S \S}$ & $271.7 \pm 23$ & $193.7 \pm 8.5$ & $196.4 \pm 12.2$ \\
\hline $\begin{array}{l}\text { Total cholesterol } \\
(\mathrm{mg} / \mathrm{dl})\end{array}$ & $88.9 \pm 1.9$ & $100.4 \pm 5.3^{\S}$ & $116.4 \pm 8.1$ & $105.1 \pm 3.9$ & $96.5 \pm 4.3$ \\
\hline $\begin{array}{l}\text { HDL-cholesterol } \\
(\mathrm{mg} / \mathrm{dl})\end{array}$ & $61.4 \pm 1.3$ & $48.8 \pm 0.9^{\S \S \S}$ & $59.4 \pm 2.6^{\phi \phi}$ & $53.7 \pm 1.0^{\phi \phi}$ & $55.3 \pm 1.7^{\phi \phi}$ \\
\hline Atherogenic index & $1.45 \pm 0.01$ & $2.02 \pm 0.37^{\S \S \S}$ & $1.87 \pm 0.05$ & $1.96 \pm 0.06$ & $1.74 \pm 0.04^{\phi}$ \\
\hline $\begin{array}{l}\text { Free fatty acids } \\
(m M)\end{array}$ & $0.79 \pm 0.04$ & $1.13 \pm 0.04^{\S \S \S}$ & $0.81 \pm 0.07^{\phi \phi \phi}$ & $0.79 \pm 0.06^{\phi \phi \phi}$ & $0.69 \pm 0.09^{\phi \phi \phi}$ \\
\hline
\end{tabular}

$\S \mathrm{P}<0.05, \S \S \S \mathrm{P}<0.001$ vs GK rats; $\phi \mathrm{P}<0.05, \phi \phi \mathrm{P}<0.01, \phi \phi \phi \mathrm{P}<0.001$ vs GKAD rats.

Table 3. Effects of atorvastatin $(G K A D+A)$, insulin $(G K A D+I)$ and the association of both $(G K A D+A+I)$ on oxidative stress parameters (8-isoprostranes and carbonyl groups), aortic nitrite/nitrate levels and CRP in atherogenic diet fed GK (GKAD) rats (mean \pm SEM of 8-16 animals).

\begin{tabular}{|c|c|c|c|c|c|}
\hline & GK & GKAD & GKAD+A & GKAD+I & $\mathbf{G K A D}+\mathbf{A}+\mathbf{I}$ \\
\hline $\begin{array}{l}\text { 8-Isoprostane } \\
(n g / 24 h)\end{array}$ & $23.1 \pm 2.26$ & $19.6 \pm 1.1$ & $25.5 \pm 1.2^{\phi}$ & $21.8 \pm 2.7$ & $20.5 \pm 2.1$ \\
\hline $\begin{array}{l}\text { Carbonyl groups } \\
(\mathrm{mmol} / \mathrm{ml})\end{array}$ & $23.5 \pm 1.1$ & $38.1 \pm 3.0^{\S \S \S}$ & $31.0 \pm 2.2$ & $35.8 \pm 3.7$ & $33.8 \pm 2.7$ \\
\hline $\begin{array}{l}\text { Nitrite/nitrate levels } \\
\text { (pmol/mg dry wt aorta) }\end{array}$ & $280.3 \pm 11.9$ & $232.4 \pm 14.9^{\S}$ & $263.0 \pm 6.4$ & $218.7 \pm 12.6^{\S \S \S}$ & $285.6 \pm 4.9^{\phi}$ \\
\hline $\begin{array}{l}C R P \\
(\mu g / m l)\end{array}$ & $34.4 \pm 1.2$ & $43.3 \pm 3.2^{\S}$ & $35.4 \pm 3.4$ & $41.0 \pm 5.4$ & $31.0 \pm 3.7^{\phi}$ \\
\hline
\end{tabular}

$\S \mathrm{P}<0.05, \S \S \S \mathrm{P}<0.001$ vs $\mathrm{GK}$ rats; $\phi \mathrm{P}<0.05$ vs GKAD rats.

lower. The levels of total cholesterol and triglycerides remained high and did not change in the different GKAD groups while HDL-cholesterol levels significantly increased with all therapeutic approaches (Table 2). Additionally, all GKAD treated groups showed a decrement in FFAs levels. Moreover, atorvastatin and insulin in combination was the only treatment able to significantly reduce atherogenic index (Table 2).

Atherogenic diet significantly increased carbonyl groups and CRP levels while a decrement in aortic nitrite/nitrate levels occurred. The different therapeutic approaches failed to diminish urinary 8-isoprostranes and plasma carbonyl compounds. Atorvastatin in association with insulin, significantly increased aortic nitrite/nitrate levels. CRP levels were not significantly different between GKAD rats and the groups treated with atorvastatin or insulin while the therapeutic combination of atorvastatin and insulin significantly decreased these levels (Table 3).

As it was found in our previous experiments, 6 months old GK rats endothelium-mediated vascular relaxation of phenylephrine-precontracted aorta arterial rings in response to ACh was impaired compared with age-matched Wistar rats, but the endotheliumindependent relaxations to SNP were similar in both strains (Sena et al. 2011). Atherogenic diet significantly impaired vascular relaxation in response to $\mathrm{ACh}$ in GK rats. Maximal endothelium-mediated relaxation of phenylephrine-precontracted rings in response to $\mathrm{ACh}$ declined by $15 \%$ when compared with control GK rats (Fig. 1). Noteworthy treatment with insulin further impaired endothelial dysfunction and supplementation 


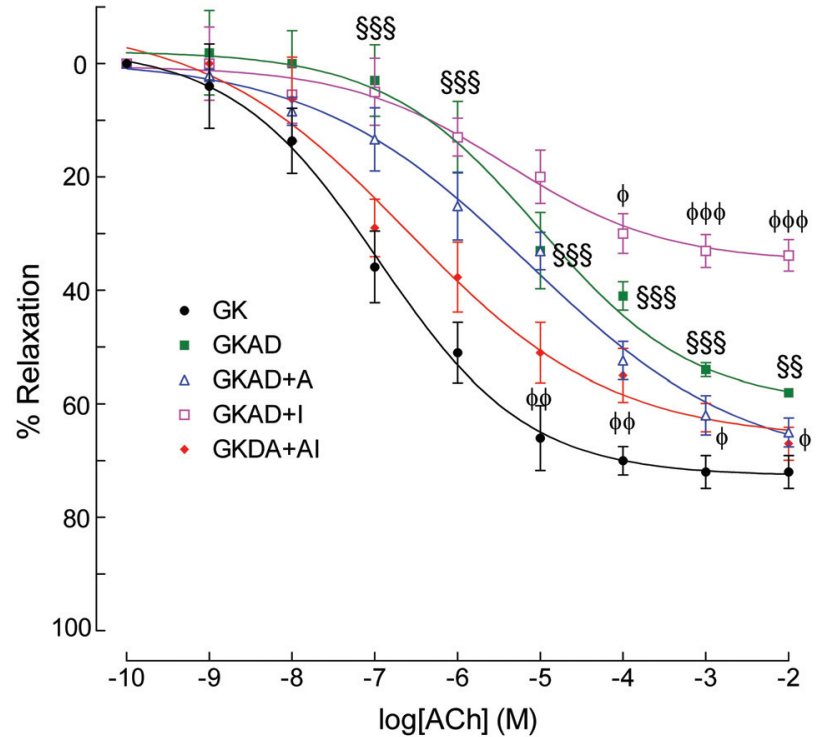

Fig. 1. Effects of high-fat diet (GKAD), atorvastatin $(G K A D+A)$, insulin (GKAD+I) and atorvastatin+insulin (GKAD+A+I) treatment on vasodilatory responses to acetylcholine in GK rats after phenylephrine preconstriction of aortic segments. Vasorelaxation was measured using an isometric force displacement transducer. Data are expressed as mean \pm SEM $(n=16)$. §§ $P<0.01, \S \S \S P<0.001$ vs GK rats; $\phi P<0.05$, $\phi \phi \mathrm{P}<0.01, \phi \phi \phi \mathrm{P}<0.001$ vs GKAD rats.

with atorvastatin and atorvastatin + insulin improved endothelium-dependent relaxation in response to $\mathrm{ACh}$ (Fig. 1). No differences on maximal relaxation were observed in the dose-response curves for SNP between the different groups (Fig. 2). Vascular sensitivity to SNP was decreased in GKAD rats (Fig. 2). Indeed, $\mathrm{pD}_{2}$ values of GKAD were significantly decreased when compared with age-matched controls $(5.42 \pm 0.03$ in GKAD vs $6.43 \pm 0.04$ in GK control rats, $\mathrm{p}<0.001)$. Atorvastatin alone or in association with insulin significantly improved endothelium-independent vascular relaxation (Fig. 2) with an increment in $\mathrm{pD}_{2}$ value (GKAD+A 5.77 $\pm 0.096, \mathrm{p}<0.001$ vs GKAD; GKAD $+\mathrm{A}+\mathrm{I}$ 6.2 \pm 0.04 , $\mathrm{p}<0.001$ vs GKAD). These results indicated that treatment with atorvastatin and insulin in combination was able to improve endothelial dysfunction in GKAD rats.

\section{Discussion}

Endothelial dysfunction is a hallmark of diabetes and insulin-resistant states and is characterized by reduced effective vascular NO action (McFarlane et al. 2002). An appropriate balance between NO, a vasodilator, and ET-1, a vasoconstrictor, is struck when the endothelium is functioning normally (von Haehling et al. 2003). Endothelial dysfunction may manifest as an

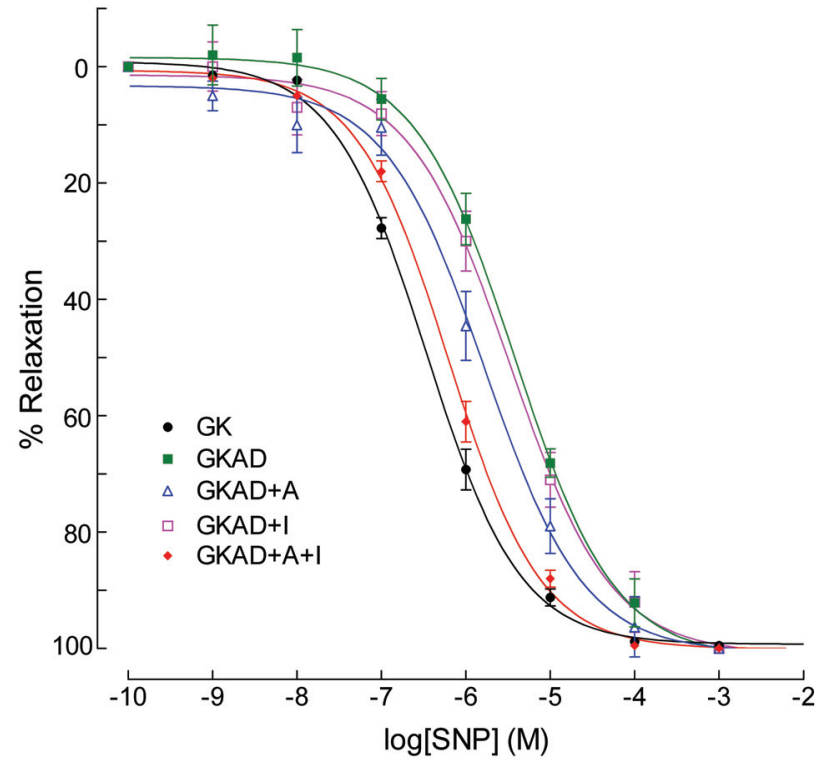

Fig. 2. Effects of high-fat diet (GKAD), atorvastatin $(G K A D+A)$, insulin (GKAD+I) and atorvastatin+insulin (GKAD+A+I) treatment on vasodilatory responses to sodium nitroprusside in GK rats after phenylephrine preconstriction of aortic segments. Vasorelaxation was measured using an isometric force displacement transducer. Data are expressed as mean \pm SEM $(n=16)$.

imbalance between vasodilation and vasoconstriction (Sena et al. 2013).

In this work we show that atherogenic diet induced an increment in carbonyl stress, inflammation, fasting glycemia, lipid profile, atherogenic index and endothelial dysfunction when compared with control GK rats. In accordance, it is well known that atherogenic diets promote dyslipidemia, insulin resistance and endothelial dysfunction in several rodent models (Fernández-Real and Ricart 2003).

In this study we show that atorvastatin treatment was beneficial on glucose metabolism (fasting glucose and $2 \mathrm{~h}$ glucose). When compared with control GK rats, atorvastatin treatment resulted in an improvement of fasting and $2 \mathrm{~h}$ glucose (ip glucose tolerance test). This observation is consistent with previous studies that showed that statin therapy can improve the parameters of glucose metabolism in diabetic and nondiabetic patients (Paniagua et al. 2002, Costa et al. 2003, Sonmez et al. 2003, Watts et al. 2003, Güclü et al. 2004). High-dose statin therapy, however, deteriorates glycemic control in patients with diabetes (Simsek et al. 2012). Additionally, monotherapy with atorvastatin was able to decrement FFAs, HOMA and augment HDL-cholesterol and improved endothelial function. An improvement in HOMA index indicates that insulin resistance is ameliorated due to a decrement in fasting glucose. 
However, it is unclear whether this improvement was achieved by decreased gluconeogenesis or by increased uptake of glucose in muscle and fat, or both. Previous studies indicated that the flux and turnover of portal freefatty acids is crucial for the development of insulin resistance (Kabir et al. 2005). Indeed, we observe an inhibition of FFAs levels after treatment with atorvastatin in addition to the decrement in insulin resistance index (HOMA).

Treatment with $10 \mathrm{mg} / \mathrm{kg}$ atorvastatin in our experimental conditions did not affect the levels of total cholesterol and triglycerides compared to control GK group. Importantly, HDL-cholesterol levels significantly increased while total-cholesterol remained unchanged. Similar results were obtained by others (Hayashi et al. 2005, Nagotani et al. 2005, Tanaka et al. 2007) with identical doses of atorvastatin in other animal models. Other studies have shown large discrepancies in the effectiveness of HMG-CoA inhibitor in lowering plasma cholesterol levels among animal species (Endo et al. 1979).

Treatment with insulin as monotherapy was also able to decrement fasting glucose and FFAs and to improve insulin resistance indexes and augment HDLcholesterol levels. Importantly, these metabolic effects were not effective to promote beneficial outcomes at the endothelium level as in the atorvastatin treated groups. All therapies failed to reduce the oxidative stress parameters evaluated. Insulin treated groups received human insulin according to their glycemic levels; as in humans. Importantly, there were no episodes of hypoglycemia, under our conditions, and normoglycemia was not achieved. Additionally, insulin treatment had no effect on daily food intake and on levels of triglycerides. This corroborates the lack of anabolic effect of insulin observed in our experimental conditions. In agreement with our study, Suzuki and co-workers (2007) have treated GK rats (for 5 weeks) without any effects on body weight.

Herein, we have shown that supplementation with atorvastatin and insulin in combination decreased blood glucose, FFAs, atherogenic index, CRP and improved insulin resistance indexes, aortic nitrite/nitrate levels and endothelial dysfunction in GKAD rats.

In agreement with our studies, it was previously described that statins ameliorate the abnormal vascular relaxation and partially restore NO production in the aorta of diabetic mice (Lefer et al. 2001). Previously studies have suggested that statins may help to correct the imbalance between vasodilation and vasoconstriction by enhancing the activity of eNOS and thus increasing the production of NO (Laufs et al. 1998). They may also reduce the synthesis of ET-1 (Hernandez-Perera et al. 1998, Puddu et al. 2001). Furthermore, it was previously shown that after 4 weeks of therapy with simvastatin there was an increment in the NO-mediated vasodilation. This effect appeared to be independent of simvastatin's lipid-lowering effects (O'Driscoll et al. 2007). It was previously described that statins increase the expression of eNOS (Laufs and Liao 1998), but also enhance eNOS activity by decreasing caveolin abundance (Feron et al. 2001) and by activation of the phosphatidylinositol 3-kinase (PI-3K)/Akt pathway (Kureishi et al. 2000). Statins have also been shown to increase GTP cyclohydrolase 1 mRNA expression in endothelial cells and to elevate intracellular tetrahydrobiopterin $\left(\mathrm{BH}_{4}\right)$ levels (Hattori et al. 2003).

Other authors suggested that atorvastatin can exhert anti-oxidant, anti-inflammatory benefits (Wagner et al. 2000, Mason et al. 2004) an effect that was not seen in our experimental conditions. Previous studies have shown that different statins are able to decrement CRP levels in both animal models and humans (Devaraj et al. 2011). New pleiotropic effects have been suggested for statins. The Justification for the Use of statins in Primary prevention: an Intervention Trial Evaluating Rosuvastatin (JUPITER) trial showed that individuals without overt cardiovascular disease, with a LDL cholesterol below the current threshold for treatment, an elevated CRP would benefit from statin therapy. Statin therapy can reduce both LDL cholesterol and hsCRP, in subjects with metabolic syndrome (Devaraj et al. 2011). In addition to the anti-inflammatory properties, the capacity of statins to alter circulating levels of several adipokines known to affect glucose homeostasis, including adiponectin, leptin, visfatin and resistin, may beneficially alter glycemic status (Kostapanos et al. 2010, Buldak et al. 2012).

Statins have been described to improve flowmediated dilation in humans (Morrow et al. 2012). Atorvastatin has been shown to normalize endothelial function and reduces oxidative stress by inhibiting vascular NADPH oxidases and preventing eNOS uncoupling by an up-regulation of GTP cyclohydrolase1 (Wenzel et al. 2008). Although atorvastatin, in our experimental conditions, did not normalize endothelial function or had anti-oxidant and anti-inflammatory properties, as previously described by others (Nissen et al. 2006, Patel et al. 2007), the animal model and the 
therapeutic (time and concentration) was considerable different and can explain the discrepancies. Importantly, atorvastatin significantly improved endotheliumdependent and independent vascular relaxation probably due to its metabolic effects. Noteworthy, supplementation with insulin impaired ACh-induced aortic relaxation, deteriorating the endothelial dysfunction observed in GKAD rats. Insulin is an essential hormone of metabolic homeostasis with a vasodilator action through PI3K/AKT pathway-dependent eNOS activation (Muniyappa et al. 2007). Insulin can also modulate eNOS activity by increasing $\mathrm{BH}_{4}$ synthesis (Shinozaki et al. 1999, Huang 2009). It has been previously described that insulin can activate the sympathetic nervous system and also stimulate the secretion of the vasoconstrictor ET-1 from vascular endothelium (Muniyappa et al. 2007), these effects can explain the aggravation of endothelial dysfunction. It was previously described that in aortas from rats with established STZ-induced diabetes, insulin leads to an enhanced aortic peroxynitrite generation and that this increment causes a dysfunction of endothelium dependent relaxation, an impairment of sarcoplasmic reticulum $\mathrm{Ca}^{2+}$ ATPases (SERCA) function. Further, it was found that addition of a peroxynitrite scavenger normalized this impaired relaxation (Kobayashi et al. 2007). These are important findings concerning the action of insulin in diabetic arteries, and in agreement with our results suggest that an insulin-induced production of peroxynitrite may be involved in mediating diabetic complications.

Furthermore, in this work we also show that atorvastatin in combination with insulin improves endothelial function to a greater extent than monotherapy with atorvastatin and significantly decreases atherogenic index and CRP levels in GK rats fed with an atherogenic diet. Noteworthy, monotherapy with atorvastatin was able to reduce fasting glucose, FFAs and improved insulin resistance indexes and endothelial function. All therapeutic approaches failed to reduce oxidative stress in Goto-Kakizaki rats fed with an atherogenic diet. Thus, the therapeutic association of atorvastatin and insulin ameliorated endothelial dependent vasodilation in GKAD rats by a mechanism that is likely due to an increment in aortic NO bioavailability and a decrement in systemic inflammation.

In conclusion, atherogenic diet induced an increment in carbonyl stress, inflammation, fasting glycemia, lipid profile and endothelial dysfunction when compared with control GK rats. Noteworthy, supplementation with insulin deteriorated endothelial dysfunction while atorvastatin induced an improvement. Atorvastatin and insulin therapies in combination decreased CRP, atherogenic index, FFAs and improved endothelial dysfunction and insulin resistance indexes in GKAD rats. The therapeutic association of atorvastatin and insulin provided a better metabolic control with a reduction in endothelial dysfunction in GKAD rats by a mechanism that involves an increment in $\mathrm{NO}$ bioavailability an improvement in systemic inflammation.

\section{Conflict of Interest}

There is no conflict of interest.

\section{Acknowledgements}

We wish to thank Laboratory of Experimental research for animal care. The present work was supported by FCT, projects PTDC/SAU-MET/115635/2009 and PestC/SAU/UI3282/2011.

\section{References}

BULDAK L, DULAWA-BULDAK A, LABUZEK K, OKOPIEN B: Effects of 90-day hypolipidemic treatment on insulin resistance, adipokines and proinflammatory cytokines in patients with mixed hyperlipidemia and impaired fasting glucose. Int J Clin Pharmacol Ther 50: 805-813, 2012.

COSTA A, CASAMITJANA R, CASALST E, ALVAREZ L, MORALES J, MASRAMON X, HERNANDEZ G, GOMIS R, CONGET I: Effects of atorvastatin on glucose homeostasis, postprandial triglyceride response and C-reactive protein in subjects with impaired fasting glucose. Diabetic Med 20: 743-745, 2003.

DEVARAJ S, SIEGEL D, JIALAL I: Statin therapy in metabolic syndrome and hypertension Post-JUPITER: what is the value of CRP. Curr Atheroscle Rep 13: 31-42, 2011.

ENDO A, TSUJITA Y, KURODA M, TAZAWA K: Effects of ML-236B on cholesterol metabolism in mice and rats: lack of hypocholesterolemic activity in normal animals Biochim Biophys Acta 575: 266-276, 1979.

FERNÁNDEZ-REAL JM, RICART W: Insulin resistance and chronic cardiovascular inflammatory syndrome. Endocrine Rev 24: 278-301, 2003. 
FERON O, DESSY C, DESAGER JP, BALLIGAND JL: Hydroxy-methylglutaryl-coenzyme A reductase inhibition promotes endothelial nitric oxide synthase activation through a decrease in caveolin abundance. Circulation 103: 113-118, 2001.

GÜCLÜ F, ÖZMEN B, HEKIMSOY Z, KIRMAZ C: Effects of statin group drug, pravastatin, on the insulin resistance in patients with metabolic syndrome. Biomed Pharmakother 58: 614-618, 2004.

HATTORI Y, NAKANISHI N, AKIMOTO K, YOSHIDA M, KASAI K: HMG-CoA reductase inhibitor increases GTP cyclohydrolase I mRNA and tetrahydrobiopterin in vascular endothelial cells. Arterioscler Thromb Vasc Biol 23: 176-182, 2003.

HAYASHI T, HAMAKAWA K, NAGOTANI S, JIN G, LI F, DEGUCHI K, SEHARA Y, ZHANG H, NAGANO I, SHOJI M, ABE K: HMG CoA reductase inhibitors reduce ischemic brain injury of Wistar rats through decreasing oxidative stress on neurons. Brain Res 1037: 52-58, 2005.

HERNANDEZ-PERERA O, PEREZ-SALA D, NAVARRO-ANTOLIN J: Effects of the 3-hydroxy-3-methylglutarylCoA reductase inhibitors, atorvastatin and simvastatin, on the expression of endothelin-1 and endothelial nitric oxide synthase in vascular endothelial cells. J Clin Invest 101: 2711-2719, 1998.

HUANG PL: eNOS, metabolic syndrome and cardiovascular disease. Trends Endocrinol Metab 20: 295-302, 2009.

II M, LOSORDO DW: Statins and the endothelium. Vascular Pharmacol 46: 1-9, 2007.

KABIR M, CATALANO KJ, ANANTHNARAYAN S, KIM SP, VAN CITTERS GW, DEA MK, BERGMANN RN: Molecular evidence supporting the portal theory: a causative link between visceral adiposity and hepatic insulin resistance. Am J Physiol Endocrinol Metab 288: E454-E461, 2005.

KOBAYASHI T, TAGUCHI K, TAKENOUCHI Y, MATSUMOTO T, KAMATA K: Insulin-induced impairment via peroxynitrite production of endothelium-dependent relaxation and sarco/endoplasmic reticulum $\mathrm{Ca}^{2+}$-ATPase function in aortas from diabetic rats. Free Radical Biology \& Medicine 43: 431-443, 2007.

KOH KK, SAKUMA I, MICHAEL J, QUON MJ: Differential metabolic effects of distinct statins. Atherosclerosis 215: $1-8,2011$.

KUREISHI Y, LUO Z, SHIOJIMA I, BIALIK A, FULTON D, LEFER DJ, SESSA WC, WALSH K: The HMG-CoA reductase inhibitor simvastatin activates the protein kinase Akt and promotes angiogenesis in normocholesterolemic animals. Nat Med 6: 1004-1010, 2000.

LAUFS U, LIAO JK: Post-transcriptional regulation of endothelial nitric oxide synthase mRNA stability by Rho GTPase. J Biol Chem 273: 24266-24271, 1998.

LAUFS U, LA FATA J, PLUTZKY J, LIAO JK: Upregulation of endothelial nitric oxide synthase by HMG CoA reductase inhibitors. Circulation 97: 1129-1135, 1998.

LEFER DJ, SCALIA R, JONES SP, SHARP BR, HOFFMEYER MR, FARVID AR, GIBSON MF, LEFER AM: HMG-CoA reductase inhibition protects the diabetic myocardium from ischemia-reperfusion injury. FASEB $J$ 15: 1454-1456, 2001.

MAJITHIYA JB, PARMAR AN, BALARAMAN R: Pioglitazone, a PPAR $\gamma$ agonist, restores endothelial function in aorta of streptozotocin-induced diabetic rats. Cardiovasc Res 66: 150-161, 2005.

MASON RP, WALTER MF, JACOB RF: Effects of HMG-CoA reductase inhibitors on endothelial function: role of microdomains and oxidative stress. Circulation 109: II34-II41, 2004.

MCFARLANE SI, MUNIYAPPA R, FRANCISCO R, SOWERS JR: Pleiotropic effects of statins: lipid reduction and beyond. J Clin Endocrinol Metab 87: 1451-1458, 2002.

MUNIYAPPA R, MONTAGNANI M, KWANG KON KOH KK, QUON MJ: Cardiovascular actions of insulin. Endocr rev 28: 463-491, 2007.

MURROW JR, SHER S, ALI S, UPHOFF I, PATEL R, PORKERT M, LE NA, JONES D, QUYYUMI AA: The differential effect of statins on oxidative stress and endothelial function: atorvastatin versus pravastatin. $J$ Clin Lipidol 6: 42-49, 2012.

NAGOTANI S, HAYASHI T, SATO K, ZHANG W, DEGUCHI K, NAGANO I, SHOJI M, ABE K: Reduction of cerebral infarction in stroke-prone spontaneously hypertensive rats by statins associated with amelioration of oxidative stress. Stroke 36: 670-672, 2005. 
NISSEN SE, NICHOLLS SJ, SIPAHI I, LIBBY P, RAICHLEN JS, BALLANTYNE CM, DAVIGNON J, ERBEL R, FRUCHART JC, TARDIF JC, SCHOENHAGEN P, CROWE T, CAIN V, WOLSKI K, GOORMASTIC M, TUZCU EM: Effect of very high-intensity statin therapy on regression of coronary atherosclerosis: the ASTEROID trial. JAMA 295: 1556-1565, 2006.

O'DRISCOLL G, GREEN D, TAYLOR RR: Simvastatin, an HMG-coenzyme A reductase inhibitor, improves endothelial function within 1 month. Circulation 95: 1126-1131, 1997.

PANIAGUA JA, LOPEZ-MIRANDA J, ESCRIBANO A, BARRAL FJ, MARIN C, BRAVO D, PAZ-ROJAS E, GOMEZ P, BARCOS M, MORENO JA, PEREZ-JIMENEZ F: Cerivastatin improves insulin sensitivity and insulin secretion in early-state obese type 2 diabetes. Diabetes 51: 2596-2603, 2002.

PATEL TN, SHISHEHBOR MH, BHATT DL: A review of high-dose statin therapy: targeting cholesterol and inflammation in atherosclerosis. Eur Heart J 28: 664-672, 2007.

PUDDU P, PUDDU GM, MUSCARI A: HMG-CoA reductase inhibitors: is the endothelium the main target? Cardiology 95: 9-13, 2001.

SENA CM, NUNES E, LOURO T, PROENÇA T, FERNANDES R, BOARDER MR, SEIÇA RM: Effects of alphalipoic acid on endothelial function in aged diabetic and high-fat fed rats. Br J Pharmacol 153: 894-906, 2008.

SENA CM, MATAFOME P, LOURO T, NUNES E, FERNANDES R, SEIÇA RM: Metformin restores endothelial function in aorta of diabetic rats. Br J Pharmacol 163: 424-437, 2011.

SENA CM, PEREIRA AM, SEIÇA R: Endothelial dysfunction - a major mediator of diabetic vascular disease. Biochim Biophys Acta 1832: 2216-2231, 2013.

SHINOZAKI K, KASHIWAGI A, NISHIO Y, OKAMURA T, YOSHIDA Y, MASADA M, TODA N, KIKKAWA R: Abnormal biopterin metabolism is a major cause of impaired endothelium-dependent relaxation through nitric oxide/O2- imbalance in insulin-resistant rat aorta. Diabetes 48: 2437-2445, 1999.

SIMSEK S, SCHALKWIJK CG, WOLFFENBUTTEL BH: Effects of rosuvastatin and atorvastatin on glycaemic control in Type 2 diabetes - the CORALL study. Diabet Med 29: 628-631, 2012.

SONMEZ A, BAYKAL Y, KILIC M, YILMAZ MI, SAGLAM K, BULUCU K, KOCAR H: Fluvastatin improves insulin resistance in non-diabetic dyslipidemic patients. Endocrine 22: 151-153, 2003.

SUZUKI N, AIZAWA T, ASANUMA N, SATO Y, KOMATSU M, HIDAKA H, ITOH N, YAMAUCHI K, HASHIZUME K: An early insulin intervention accelerates pancreatic beta-cell dysfunction in young GotoKakizaki rats, a model of naturally occurring noninsulin-dependent diabetes. Endocrinology 138: 1106-1110, 1997.

TAKEMOTO M, LIAO JK: Pleiotropic effects of 3-hydroxy-3-methylglutarylcoenzyme A reductase inhibitors. Arterioscler Thromb Vasc Biol 21: 1712-1719, 2001.

TANAKA N, KATAYAMA Y, KATSUMATA T, OTORI T, NISHIYAMA Y: Effects of long-term administration of HMG-CoA reductase inhibitor, atorvastatin, on stroke events and local cerebral blood flow in stroke-prone spontaneously hypertensive rats. Brain Res 1169: 125-132, 2007.

VON HAEHLING S, ANKER S, BASSENGE E: Statins and the role of nitric oxide in chronic heart failure. Heart Fail $\operatorname{Rev}$ 8: 99-106, 2003.

WAGNER AH, KOHLER T, RUCKSCHLOSS U, JUST I, HECKER M: Improvement of nitric oxide-dependent vasodilatation by HMG-CoA reductase inhibitors through attenuation of endothelial superoxide anion formation. Arterioscler Thromb Vasc Biol 20: 61-69, 2000.

WATTS GF, BARRETT HR, JI J, SERONE AP, CHAN DC, CROFT KD, LOEHRER F, JOHNSON AG: Differential regulation of lipoprotein kinetics by atorvastatin and fenofibrate in subjects with the metabolic syndrome. Diabetes 52: 803-811, 2003.

WENZEL P, DAIBER A, OELZE M, BRANDT M, CLOSS E, XU J, THUM T, BAUERSACHS J, ERTL G, ZOU H, FÖRSTERMANN U, MÜNZEL T: Mechanisms underlying recoupling of eNOS by HMG-CoA reductase inhibition in a rat model of streptozotocin-induced diabetes mellitus. Atherosclerosis 198: 65-76, 2008. 